Portland State University

PDXScholar

4-1-2008

\title{
Bioinspired broadband antireflection coatings on GaSb
}

\author{
Wei-Lun Min \\ University of Florida \\ Amaury P. Betancourt \\ University of Florida \\ Peng Jiang \\ University of Florida \\ Bin Jiang \\ Portland State University
}

Follow this and additional works at: https://pdxscholar.library.pdx.edu/mth_fac

Part of the Mathematics Commons

Let us know how access to this document benefits you.

\section{Citation Details}

Wei-Lun, M., Betancourt, A. P., Peng, J., \& Bin, J. (2008). Bioinspired broadband antireflection coatings on GaSb. Applied Physics Letters, 92(14), 141109

This Article is brought to you for free and open access. It has been accepted for inclusion in Mathematics and Statistics Faculty Publications and Presentations by an authorized administrator of PDXScholar. Please contact us if we can make this document more accessible: pdxscholar@pdx.edu. 


\title{
Bioinspired broadband antireflection coatings on GaSb
}

\author{
Wei-Lun Min, ${ }^{1}$ Amaury P. Betancourt, ${ }^{1}$ Peng Jiang, ${ }^{1, a)}$ and Bin Jiang ${ }^{2}$ \\ ${ }^{1}$ Department of Chemical Engineering, University of Florida, Gainesville, Florida 32611, USA \\ ${ }^{2}$ Department of Mathematics and Statistics, Portland State University, Portland, Oregon 97201, USA
}

(Received 20 February 2008; accepted 23 March 2008; published online 9 April 2008)

\begin{abstract}
We report an inexpensive yet scalable templating technique for fabricating moth-eye antireflection gratings on gallium antimonide substrates. Non-close-packed colloidal monolayers are utilized as etching masks to pattern subwavelength-structured nipple arrays on GaSb. The resulting gratings exhibit superior broadband antireflection properties and thermal stability than conventional multilayer dielectric coatings. The specular reflection of the templated nipple arrays match with the theoretical predictions using a rigorous coupled-wave analysis model. The effect of the nipple shape and size on the antireflection properties has also been investigated by the same model. These biomimetic coatings are of great technological importance in developing efficient thermophotovoltaic cells. (C) 2008 American Institute of Physics. [DOI: 10.1063/1.2908221]
\end{abstract}

Thermophotovoltaic (TPV) cells convert radiation from high-temperature materials to electrical charges that are utilized to power an external circuit. ${ }^{1-3}$ Gallium antimonide $(\mathrm{GaSb})$ is one of the most appropriate materials for TPV generation due to the excellent match between the radiation spectrum and the spectral response of GaSb cells. ${ }^{4}$ Unfortunately, approximately $40 \%$ of the incident radiation is reflected back from the cell surface due to the high refractive index (RI) of GaSb. ${ }^{2}$ Vacuum deposited multilayer dielectric films (e.g., $\mathrm{ZnS} / \mathrm{MgF}_{2}$ ) have been utilized as antireflection coatings (ARCs) for reducing the unwanted reflective losses. ${ }^{5}$ However, these multilayer coatings are expensive to fabricate and they can only suppress reflection over a narrow range of wavelengths. Additionally, the thermal stability of the multilayer ARCs is poor due to the mismatch of the thermal expansion coefficient between the substrate and the coatings.

One promising way to fabricate broadband ARCs is to pattern subwavelength-structured gratings directly on $\mathrm{GaSb}$ substrates. ${ }^{5}$ This is inspired by the grainy microstructures on the corneas of moths, which consist of a non-close-packed (NCP), hexagonal array of subwavelength conical nipples. ${ }^{6,7}$ These nipples can greatly reduce reflection by creating a RI gradient across the interface between air and cornea. Besides broadband antireflection, the moth-eye gratings are also intrinsically more stable and durable than multilayer ARCs since no foreign material is involved. ${ }^{8,9}$ However, current production of moth-eye ARCs is greatly impeded by the expensive top-down fabrication technologies. ${ }^{8-14}$ For instance, e-beam lithography (EBL) has been utilized to create tapered gratings on $\mathrm{GaSb}$ substrates that decrease the reflection to $5 \%-10 \%{ }^{5}$ Unfortunately, EBL is expensive and the low throughput is a major concern.

We have recently developed a simple yet scalable templating technology for patterning moth-eye gratings on single-crystal silicon substrates. ${ }^{15,16}$ Hexagonal monolayers of silica colloids prepared by an inexpensive spin-coating technique are used as etching masks during conventional reactive ion etching (RIE). ${ }^{16}$ Here, we demonstrate the fabrication of broadband ARCs on GaSb wafers that exhibit su-

${ }^{a)}$ Electronic mail: pjiang@che.ufl.edu. perior antireflection properties and thermal stability than conventional multilayer and EBL-patterned ARCs by using the colloidal templating approach. The effect of the nipple shape and size on the antireflection properties of moth-eye ARCs has also been systematically investigated.

The well-established spin-coating technique ${ }^{17,18}$ is used to generate NCP colloidal monolayers of hexagonally ordered silica particles embedded in a polymer matrix on a single-crystal GaSb wafer [(100) $n$-type, Galaxy Compound Semiconductors]. The polymer matrix is partially removed by oxygen plasma etching (40 mTorr, 40 SCCM (SCCM denotes cubic centimeter per minute at STP) $\mathrm{O}_{2}, 100 \mathrm{~W}$ for $2 \mathrm{~min})$. The released colloidal array can then be used as etching mask during a chlorine-RIE process $(5.3 \mathrm{mTorr}$, $8 \mathrm{SCCM} \mathrm{Cl} 2,4 \mathrm{SCCM} \mathrm{Ar}$ ) operating on a Unaxis Shuttlelock reactive ion etcher to pattern subwavelength nipple arrays. The templating silica particles can finally be removed by dissolving in a $2 \%(v / v)$ hydrofluoric acid aqueous solution. The top- and tilted-view scanning electron microscope (SEM) images in Fig. 1 illustrate the resulting microstructures etched at $150 \mathrm{~W}$ for 3 min [Figs. 1(a) and 1(b)], and

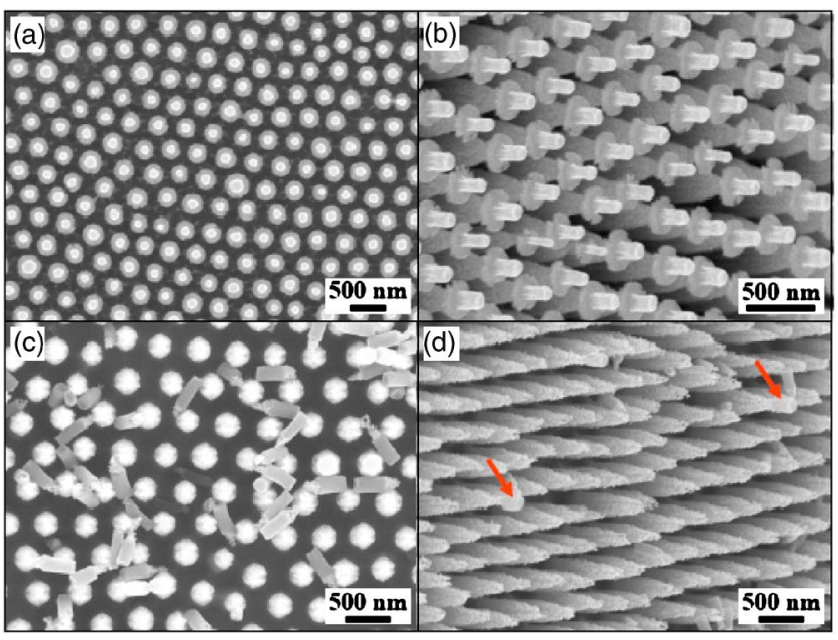

FIG. 1. (Color online) SEM images of templated GaSb nipple arrays etched at different RIE conditions. [(a) and (b)] Top and tilted view of nipple arrays etched at $150 \mathrm{~W}$ for $3 \mathrm{~min}$. [(c) and (d)] Top and tilted view of nipple arrays etched at $200 \mathrm{~W}$ for $2.5 \mathrm{~min}, 310 \mathrm{~nm}$ silica spheres are used as templates. 


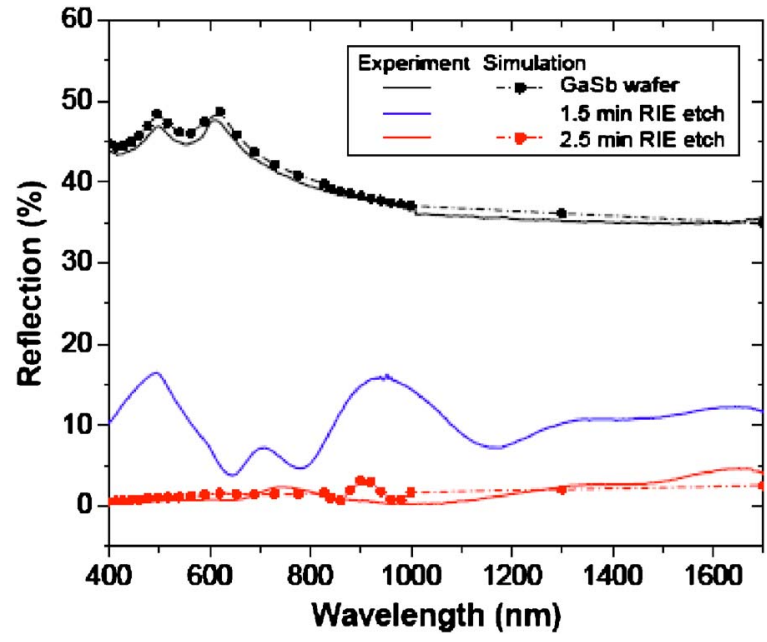

FIG. 2. (Color online) Experimental (solid) and RCWA-simulated (dotted) specular optical reflection at normal incidence. Black: bare (100) GaSb wafer. Blue: templated nipple arrays etched at $200 \mathrm{~W}$ for $1.5 \mathrm{~min}$, Red: templated nipple arrays etched at $200 \mathrm{~W}$ for $2.5 \mathrm{~min}$.

$200 \mathrm{~W}$ for $2.5 \mathrm{~min}$ [Figs. 1(c) and 1(d)]. It is evident that different etching conditions lead to different nipple geometries.

We find that the polymer wetting layer between the spincoated colloidal monolayer and the wafer surface plays an important role in the RIE patterning process. During the oxygen plasma etching, the NCP silica particles protect the underneath polymer to form cylindrical polymer posts as indicated by the bright top posts in Fig. 1(b) and the red arrows in Fig. 1(d). When the chlorine-RIE power is low $(150 \mathrm{~W})$, silica particles protect the GaSb surface immediately under the particles from being etched, resulting in the formation of the unusual candle-stand-shaped patterns as shown in Fig. 1(b). When the etching power is high $(200 \mathrm{~W})$, the isotropic etching of the GaSb substrate leads to the formation of nipples with sharp tips as shown in Fig. 1(d). Furthermore, the bottom of the polymer posts is damaged when the etching power is high as illustrated by the broken polymer posts in Fig. 1(c). These polymer posts can be easily removed by a brief oxygen plasma etching at $100 \mathrm{~W}$ for $2 \mathrm{~min}$.

The specular optical reflectivity of the templated $\mathrm{GaSb}$ nipple arrays are evaluated using visible-near-IR reflectivity measurement at normal incidence. A HR4000 UV-visible spectrometer and a NIR-512 spectrometer (both from Ocean Optics) are used to measure the reflectance from 400 to $1700 \mathrm{~nm}$. The solid lines in Fig. 2 show the measured reflection from a bare GaSb wafer and nipple arrays etched at $200 \mathrm{~W}$ for 1.5 and $2.5 \mathrm{~min}$, respectively. The wafer exhibits $>35 \%$ reflectivity for all above wavelengths, consistent with previous optical measurements. 5,19 The $1.5 \mathrm{~min}$ etched sample shows lower reflection (5\%-15\%) and the reflectivity is wavelength dependent. Much lower reflection $(<2 \%)$ is obtained when the etch duration is longer than $2.5 \mathrm{~min}$. Most importantly, the resulting subwavelength ARCs are broadband, exhibiting consistent low reflection over both visible and near-IR wavelengths.

The experimental measurements are complemented by theoretical calculations using a rigorous coupled-wave analysis (RCWA) model. ${ }^{20}$ Half-ellipsoid-shaped profile is used to simulate the templated nipples as shown in Fig. 1(d). We divide the half-ellipsoid into 100 horizontal circular layers.

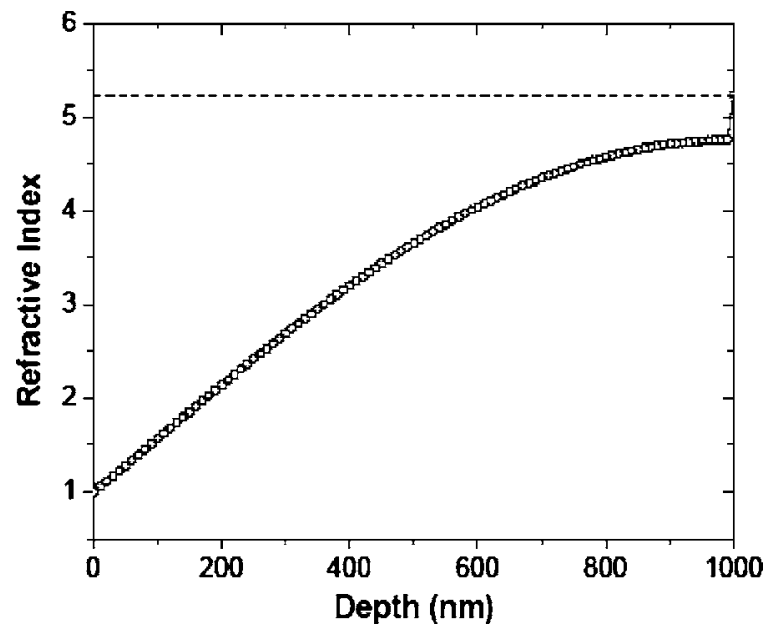

FIG. 3. Change of the calculated effective RI at $\lambda=620 \mathrm{~nm}$ from the wafer surface $($ depth $=0)$ to the bottom of templated GaSb nipples with $1000 \mathrm{~nm}$ depth. The dotted line indicates the RI of bulk GaSb at $620 \mathrm{~nm}$ wavelength.

The internipple distance is defined as $\sqrt{2} D$, where $D$ is the diameter of templating silica spheres. ${ }^{17,18}$ We can calculate the fraction of GaSb in each layer as $f\left(z^{*}\right)=\pi\left(r^{*}\right)^{2} / \sqrt{3} D^{2}$, where $z^{*}$ and $r^{*}$ are the $\mathrm{z}$ coordinate and the radius of the layer, respectively. Based on the effective medium theory, the effective RI $n\left(z^{*}\right)$ of the layer at height $z^{*}$ can be approximated by $n\left(z^{*}\right)=\left\{f\left(z^{*}\right) n_{\mathrm{GaSb}}{ }^{q}+\left[1-f\left(z^{*}\right)\right] n_{\text {air }}{ }^{q}\right\}^{1 / q}$, where $q=\frac{2}{3} \cdot{ }^{7,21}$ The complex RI of GaSb is used to calculate the reflectance. $^{19,22}$

The dotted lines in Fig. 2 show the simulated specular reflection from a bare GaSb wafer and a hexagonal array of nipples with $1000 \mathrm{~nm}$ height templated from $310 \mathrm{~nm}$ silica spheres. It is apparent that the calculated reflection from a $\mathrm{GaSb}$ wafer is very close to the measured spectrum. The simulated reflection from the templated nipple array also reasonably agrees well with the experimental spectrum. The excellent broadband antireflection properties of the templated subwavelength gratings can be easily explained by mapping the calculated effective RI at $\lambda=620 \mathrm{~nm}$ across the height of $1000 \mathrm{~nm}$ nipples (Fig. 3). For bare wafer, the RI changes sharply from air $(\mathrm{RI}=1.0)$ to bulk $\mathrm{GaSb}(\mathrm{RI}=5.239)$, while for templated nipples, the RI changes gradually from 1.0 to $\sim 4.76$ and then to 5.239. This RI gradient leads to very low reflection over a wide range of wavelengths. ${ }^{7}$

We also investigated the effect of the nipple shape and size on the antireflection properties of subwavelength ARCs using the RCWA model. Figure 4 compares the simulated normal-incidence specular reflection from nipple arrays with three types of shape-half-ellipsoid, paraboloid, and pyramid. It is evident that the paraboloid and pyramid-shaped nipples show lower reflection than half-ellipsoid nipples. We also calculate the reflectance from nipple arrays templated from different-size silica particles $(100,200,300,400$, and $500 \mathrm{~nm}$ ). The results show that the specular reflection is independent on the templated nipple size. This can be understood by considering the above formulas of $r^{*}$ and $f\left(z^{*}\right)$ which lead to $f\left(z^{*}\right)=\pi\left[1-\left(z^{*} / h\right)^{2}\right] r^{2} / \sqrt{3} D^{2}$, where $h$ is the nipple height. Since $r=\sqrt{2} / 2 D$ is always proportional to $D$ so that $r / D$ is a constant, $f\left(z^{*}\right)$ and the RI are then independent of the particle size.

Since the surface temperature of TPV cells is higher than that of a conventional solar cell, the thermal stability of the 


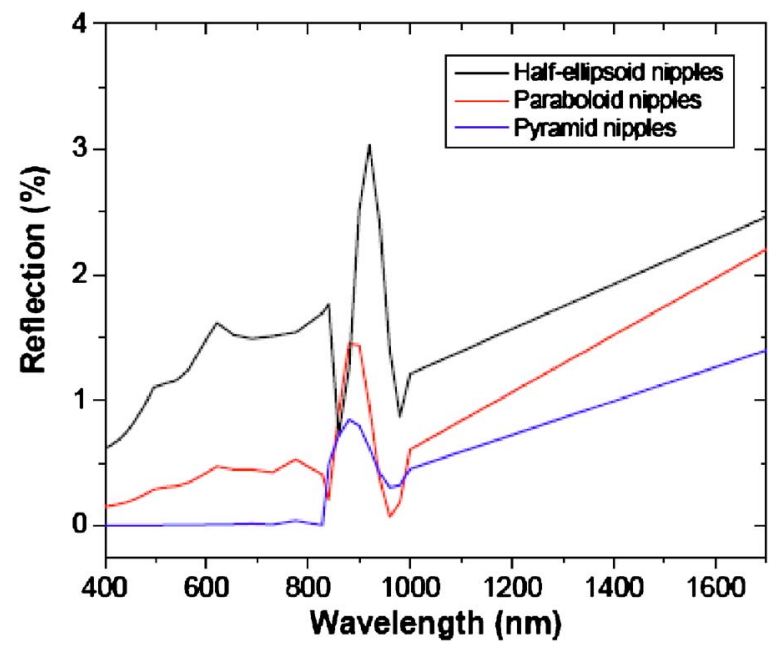

FIG. 4. (Color online) Comparison of the normal-incidence specular reflection among three types of nipples-half-ellipsoid, paraboloid, and pyramid.

templated subwavelength ARCs needs to be evaluated. We compare the normal-incidence specular reflection of the 2.5 min etched sample as shown in Fig. 2 prior to and after annealing at $200{ }^{\circ} \mathrm{C}$ for $6 \mathrm{~h}$. The results in Fig. 5 show that the change of the reflection is very small, indicating excellent thermal stability of the templated gratings. This is in

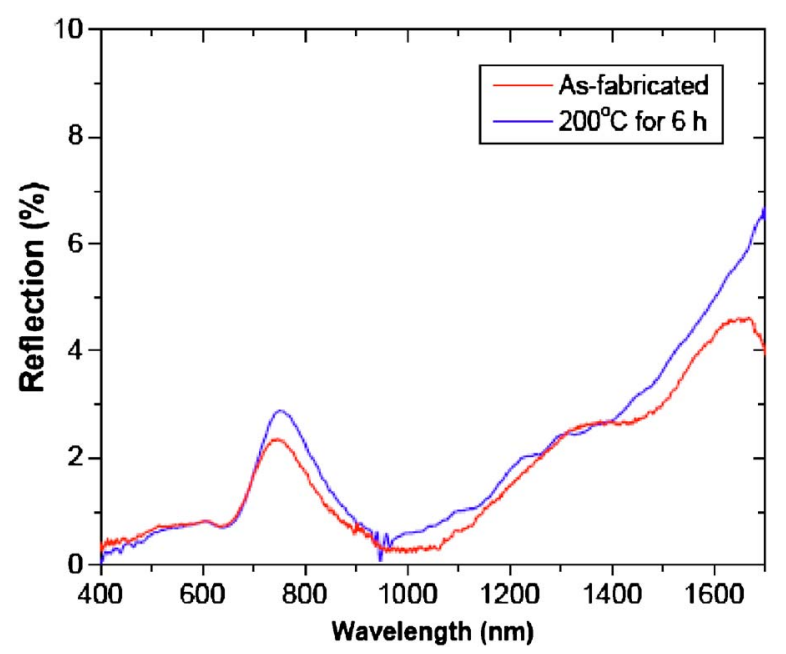

FIG. 5. (Color online) Comparison of the normal-incidence specular reflection between an as-fabricated $\mathrm{GaSb}$ grating (same as the $2.5 \mathrm{~min}$ etched sample in Fig. 2) and the same sample after annealing at $200{ }^{\circ} \mathrm{C}$ for $6 \mathrm{~h}$. sharp contrast with the conventional multilayer ARCs which exhibit significant antireflection degradation even at temperature as low as $100{ }^{\circ} \mathrm{C} .{ }^{5}$

In summary, we have developed a simple yet scalable templating approach in fabricating wafer scale, subwavelength-structured ARC directly on GaSb substrates. The resulting gratings exhibit excellent broadband antireflection properties and thermal stability. The evaluation of efficiency of GaSb TPV cells with templated moth-eye ARCs is still under investigation and will be reported in our future publication.

This work was supported by the NSF grant CBET0651780, the start-up funds from the University of Florida, and the UF Research Opportunity Incentive Seed Fund.

${ }^{1}$ S. Basu, Y. B. Chen, and Z. M. Zhang, Int. J. Energy Res. 31, 689 (2007).

${ }^{2}$ V. P. Khostikov, O. A. Khvostikova, P. Y. Gazaryan, S. V. Sorokina, N. S. Potapovich, A. V. Malevskaya, N. A. Kaluzhniy, M. Z. Shvarts, and V. M. Andreev, J. Sol. Energy Eng. 129, 291 (2007).

${ }^{3}$ V. P. Khvostikov, O. A. Khvostikova, P. Y. Gazaryan, M. Z. Shvarts, V. D. Rumyantsev, and V. M. Andreev, Semiconductors 38, 950 (2004).

${ }^{4}$ S. Luca, J. L. Santailler, J. Rothman, J. P. Belle, C. Calvat, G. Basset, A. Passero, V. P. Khvostikov, N. S. Potapovich, and R. V. Levin, J. Sol. Energy Eng. 129, 304 (2007).

${ }^{5}$ Y. Kanamori, K. Kobayashi, H. Yugami, and K. Hane, Jpn. J. Appl. Phys., Part 1 42, 4020 (2003).

${ }^{6}$ P. B. Clapham and M. C. Hutley, Nature (London) 244, 281 (1973).

${ }^{7}$ D. G. Stavenga, S. Foletti, G. Palasantzas, and K. Arikawa, Proc. R. Soc. London, Ser. B 273, 661 (2006).

${ }^{8}$ P. Lalanne and G. M. Morris, Nanotechnology 8, 53 (1997).

${ }^{9}$ Z. N. Yu, H. Gao, W. Wu, H. X. Ge, and S. Y. Chou, J. Vac. Sci. Technol. B 21, 2874 (2003).

${ }^{10}$ Y. Kanamori, K. Hane, H. Sai, and H. Yugami, Appl. Phys. Lett. 78, 142 (2001).

${ }^{11}$ Y. Kanamori, E. Roy, and Y. Chen, Microelectron. Eng. 78, 287 (2005).

${ }^{12}$ C. Lee, S. Y. Bae, S. Mobasser, and H. Manohara, Nano Lett. 5, 2438 (2005).

${ }^{13}$ S. Wang, X. Z. Yu, and H. T. Fan, Appl. Phys. Lett. 91, 061105 (2007).

${ }^{14}$ B. G. Prevo, E. W. Hon, and O. D. Velev, J. Mater. Chem. 17, 791 (2007).

${ }^{15}$ C. H. Sun, W. L. Min, N. C. Linn, P. Jiang, and B. Jiang, Appl. Phys. Lett. 91, 231105 (2007).

${ }^{16}$ C. H. Sun, P. Jiang, and B. Jiang, Appl. Phys. Lett. 92, 061112 (2008).

${ }^{17}$ P. Jiang and M. J. McFarland, J. Am. Chem. Soc. 126, 13778 (2004).

${ }^{18}$ P. Jiang, T. Prasad, M. J. McFarland, and V. L. Colvin, Appl. Phys. Lett. 89, 011908 (2006).

${ }^{19}$ D. E. Aspnes and A. A. Studna, Phys. Rev. B 27, 985 (1983).

${ }^{20}$ M. G. Moharam, D. A. Pommet, E. B. Grann, and T. K. Gaylord, J. Opt. Soc. Am. A 12, 1077 (1995).

${ }^{21}$ H. A. Macleod, Thin-Film Optical Filters, 3rd ed. (Institute of Physics, Bristol, 2001), p. 40.

${ }^{22}$ E. D. Palik, Handbook of Optical Constants of Solids, 2nd ed. (Academic, Boston, 1991), p. 603. 
Applied Physics Letters is copyrighted by the American Institute of Physics (AIP). Redistribution of journal material is subject to the AIP online journal license and/or AIP copyright. For more information, see http://ojps.aip.org/aplo/aplcr.jsp 